\title{
APLICATION OF ROBOTICS AND CNC MACHINES IN PRODUCTION
}

\author{
Original scientific paper
}

UDC: $681.518: 338.312$

https://doi.org/10.18485/aeletters.2020.5.4.4

\author{
Milan Miscevic $^{1}$, Djordje Dihovicni ${ }^{2}$ \\ ${ }^{1}$ Teximp d.o.o, Belgrade, Republic of Serbia \\ ${ }^{2}$ The Academy of Technical Applied Sciences, Bulevar Zorana Djindjica 152a, Belgrade, Republic of Serbia
}

\begin{abstract}
:
In this paper the industrial automation of the production process, which is based on the fusion of a CNC machine and an industrial robot, is described. The functional structure of the flexible production cell, its configuration, programming methods and applications in industry are explained in detail. Based on the application of artificial intelligence, an example of making a machine part with the use of machines and software of the latest generation is given. Using this approach it is achieved significant shortening of production time, increased productivity and almost total elimination of scrap. Special attention is given to the current fourth industrial revolution and the application of the CAD / CAM / CNC concept in the future.
\end{abstract}

\section{ARTICLE HISTORY}

Received: 18.11.2020.

Accepted: 14.12.2020.

Available: 31.12.2020.

\section{KEY WORDS}

Artificial intelligence, automation, industrial computing systems, robotics

\section{INTRODUCTION}

The technological process of innovation that enables production in a more automated way, and with an integrated infrastructure, consisting of assets, machines, people, mobile devices and information systems, and that could be located inside and outside of the company is called the fourth industrial revolution, or popularly Industry 4.0, [1,2]. Planning, monitoring and control of production operations is done in real time, with process and resource optimization, performance analysis and reduction of errors and scraps, thus achieving continuous progress in production, $[3,4]$. The complete research is made according to the features of this concept, which will be explained in more detail in this paper, [5-7].

As part of the research, a complete installation of a flexible production cell according to the "turnkey" system is carried out and shown at a well-known customer, a client of the company from Belgrade, Serbia.

The research is performed in the client's production plant during the installation of the complete system and its commissioning (November-December 2019). During the research, three types of measurements are performed:
- measurement of shape and dimension tolerance;

- measurement of production time;

- measuring the percentage of scrap.

The subject of the research is a flexible production cell of the latest generation consisting of two basic units, a CNC machine and an industrial robot, which are interconnected into an intelligent production system. In addition, the complete process of installing the intelligent system in the production hall of the customer will be processed.

A large number of companies in the Serbia remained technologically trapped in the period from the beginning of the third, and some even in the period of the second industrial revolution. The machine park is mostly over three decades old, which is an unsustainable situation for modern production and competitiveness on the global market [8]. The fourth industrial revolution has largely begun, and it is up to us to keep up with it, [9-11]. The significance of this research is proving on a realistic model that it has become possible to make automated production with the investment that is available today to small businesses. 
It is also characterized by ease of connection to peripheral devices (pallet changers, robots, turntables, and etc). A significant role in increasing the flexibility of the machine is played by the intuitive HAAS NGC (New Generation Control) control unit, which easily manages the machine and peripherals, monitors the entire process and communicates with the operator via text notifications on the monitor, $[12,13]$.

The aim of this paper is to examine the possibility of successful installation of an intelligent production system of the latest generation and to compare the results with the already established production systems of the older generation.

As part of the research, all the necessary steps for the successful implementation of a flexible production cell in production that meets all the prerequisites of Industry 4.0 are implemented and presented.

A comparison of two independent samples are performed, i.e. the results of measuring the parameters of the production department before and after the installation of the autonomous system.

\section{DESCRIPTION OF THE SYSTEM}

For the needs of a known customer, it was necessary to make a flexible production cell for processing a precision aluminium part with a diameter of $25 \mathrm{~mm}$ and a length of $30 \mathrm{~mm}$ (Fig.1). The planned quantities are 100,000 pieces per year for the pilot project, with a tendency to increase the quantities to 400,000 pieces per year.

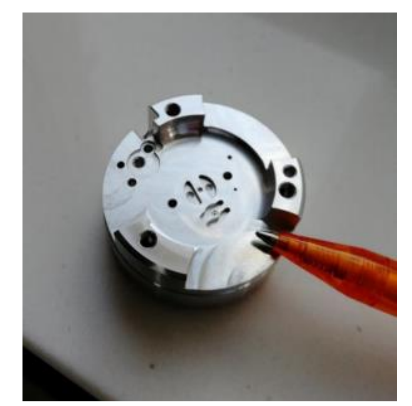

Fig.1. Appearance of the finished work

Input parameters obtained from the customer are:

- workshop drawing of the work;

- preparation material;

- planned annual quantities.

Given the expected fabrication time of approximately 4 minutes per piece, obtained by simulation in CAM software, it is determined that the machine would have to work in uniform clocks in three shifts to achieve the planned quantities. The calculation also includes the degree of safety for anticipated and unforeseen outages (regular and emergency services, tool damage, power failure, etc.). The customer is offered a solution with a vertical machining center HAAS DM-1, which is equipped with a rotating device with the fourth and fifth axis HAAS TRT100, and on which an automatic pneumatic work piece clamping system is installed, constructed and made in company TEXIMP. A universal URC robotic cell with a FANUC robotic arm was chosen to service the machine.

The HAAS DM-1 (Drill-Mill) is a compact 3-axis machining center with $15,000 \mathrm{rpm}$ on the main random spindle (Fig.3), an ISO4O conical tool holder, a warehouse with $18+1$ tool slots and an alternating arm, $[14,15]$. This machining center has high productivity due to the high speed of movement on all axes. The maximum idle offset is $61.0 \mathrm{~m} / \mathrm{min}$, while the working speed is up to 30.5 $\mathrm{m} / \mathrm{min}$.

It is also characterized by ease of connection to peripheral devices (pallet changers, robots, turntables, and etc). A significant role in increasing the flexibility of the machine is played by the intuitive HAAS NGC (New Generation Control) control unit, [16,17], which easily manages the machine and peripherals, monitors the entire process and communicates with the operator via text notifications on the monitor.

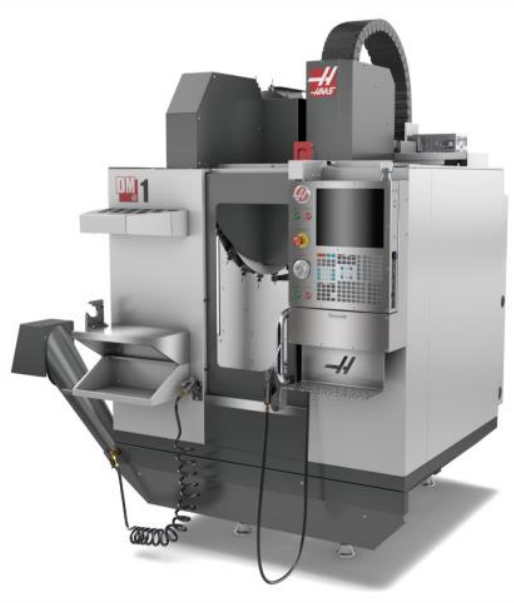

Fig.2. HAAS DM-2 (Drill/Mill Center)

HAAS TRT100 (Tilting Rotary Table $100 \mathrm{~mm}$ ) is a two-axis high-speed tilting rotary table, driven by two servo motors. It is intended for $3+2$ (index) and completely 5 -axis processing of small parts. It has a maximum load capacity on the table of up to $6.8 \mathrm{~kg}$. It is compatible with the DM series, or larger 
machines from the HAAS program. It is ideal for processing smaller parts. Using devices of this type significantly reduces the cycle time. The connection to the CNC machine is very simple and is done by plugging the communication and power connectors into the appropriate outlet on the machine's electrical cabinet, $[18,19]$.

In order for the machine to be able to run with two more axes on the device in addition to its three axes, it is necessary to have additional drivers (modules) for the fourth and fifth axes. These drivers, as well as the turntable itself, are among the accessories of the machine. By installing these options, the 3-axis vertical machining center quickly turns into a 5-axis CNC machine.

Two-axle rotary device HAAS is presented at Fig.3.

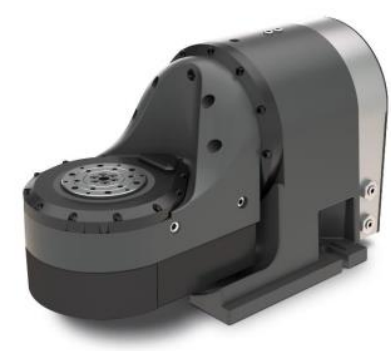

Fig.3. Two-axle rotary device HAAS TRT100

\section{AUTOMATIC CLAMPING SYSTEM AND ROBOT CELL}

A clamping head with an elastic sleeve that is installed on the turntable is required to clamp a 25 $\mathrm{mm}$ diameter work piece. Also, it is necessary that the clamping head has an automated system of clamping and releasing the piece.

The main problem is that the solutions that could be found on the market are too difficult, which would significantly affect the accuracy of the parts being processed, because the load capacity of the turntable during index rotation is $6.8 \mathrm{~kg}$, and during simultaneous rotation $3.2 \mathrm{~kg}$. For this reason, it is decided to resort to the development of a new product with the help of CAD software AUTODESK FUSION, [20,21].

Housing load simulation results are presented at Fig.4.

In realization of the task it is necessary to include few steps:

- make the concept of the contraction and the CAD model in the software package AUTODESK FUSION;
- simulate working load model in the programming environment AUTODESK FUSION;

- check the deformation of the resulting models and their influence on the given tolerances of the work piece;

- make NC program for the HAAS CNC lathe in CAM software ESPRIT;

- make a functional prototype on HAAS ST-30Y CNC lathe with $Y$-axis.

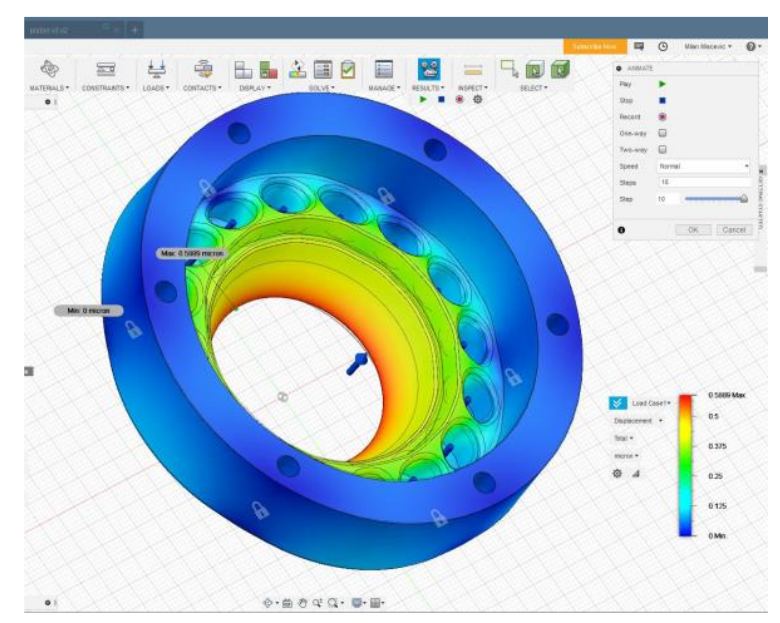

Fig.4. Housing load simulation results

For this purpose, a mechanical-pneumatic clamping head is constructed (Fig.5). In order to make the real product as light as possible for the material of the housing and the pneumatic piston, aluminium 6061-O (ISO AIMg1SiCu) is chosen. The clamping of the elastic sleeve is performed by the springs, and the release is performed by a pneumatic piston which is driven by compressed air and controlled via a pneumatic unit on a CNC machine. Control is performed via $M$-functions in the NC program of the machine (ISO / G-code). The signal is sent from the control unit to the solenoid (electro-pneumatic valve).

This clamping system solves another problem that existed in production, and that is the deformation of work pieces due to different clamping forces. The operator had to manually place the half-processed work piece in the clamp and also clamp it manually. Not in that way, with an unequal clamping force, he occasionally deformed the already processed side of the piece, which resulted in a waste of 3 to $5 \%$ on a monthly basis. Testing of pneumatic clamping systems on machine is shown at Fig.5, down below. 


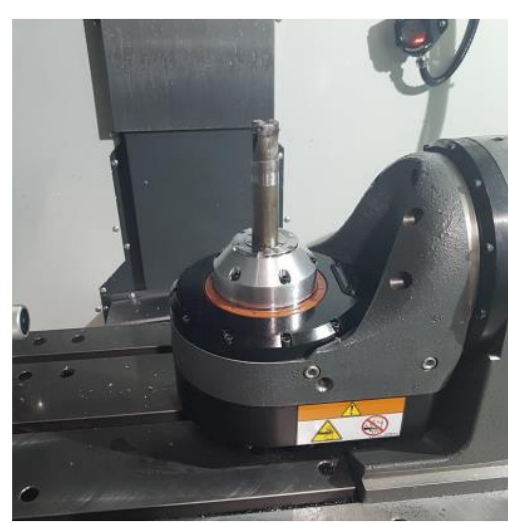

Fig.5. Robotic arm FANUC LR Mate 200iD / 7L

A Universal Robot Cell (URC), is provided, delivered and installed for manipulating the pieces and servicing the 5-axis CNC machine equipped in this way. The complete URC cell is flexible and constructed so that it can be the basis for a large number of different FANUC robot models. Also, it can be connected to a wide range of different machines. It is mainly intended for servicing CNC milling machines and $C N C$ lathes. For this purpose, an industrial robot with 6 controlled axes, anthropomorphic configuration FANUC LR Mate 200iD / 7L, load capacity 7kg (Fig.6) with two mechanical-pneumatic gripper parts manufactured by SCHUNK is used [22-24].

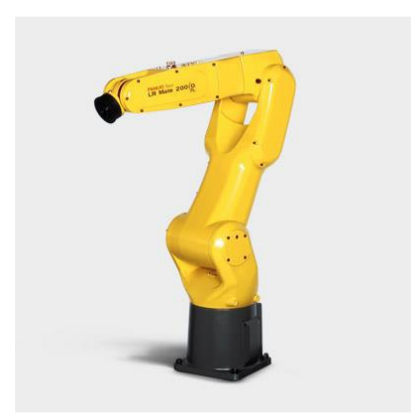

Fig.6. Testing of pneumatic clamping system

This type of robot is chosen because of the required reach length of $911 \mathrm{~mm}$, although its working capacity far exceeds the weight of the work piece. The "L" in the name is carried by the variants with extended arm (eng. Long arm).

\section{TESSTING OF THE SYSTEM}

The current situation in the client's production was as follows:

- average time of making the work - 13 minutes per piece;

- 10 CNC machines with operators in three shifts that served two machines (a total of 15 operators / skilled workers in 3 shifts);
- percentage of scrap of $3 \%$ to $5 \%$ due to deformation of the aluminum piece due to different clamping force during machining.

After connecting all the elements of the flexible production cell into one whole, generating the NC program for HAAS DM-1 in the CAM software ESPRIT, coding the cycle for process measurement with a measuring probe and programming the robot, the complete system is tested (Fig.7).

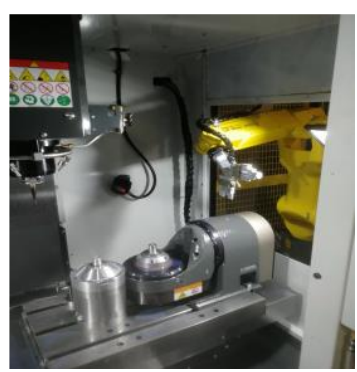

Fig.7. Testing of the complete system

A complete tactile scan of the surfaces is used during the measurement (Fig.8). With this measurement strategy, even deformations on the measured surface can be detected.

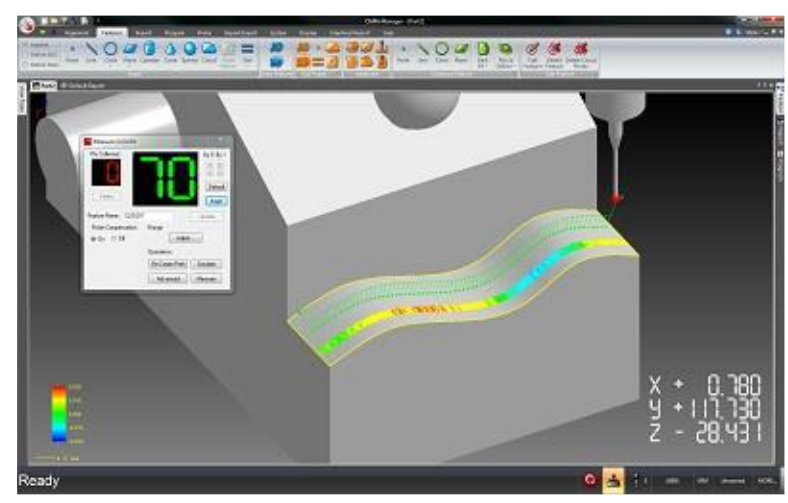

Fig.8. Example of surface scanning on CMM

It is far stricter (more precise) than tactile measurement of surfaces at points on a given pattern (Fig.9).

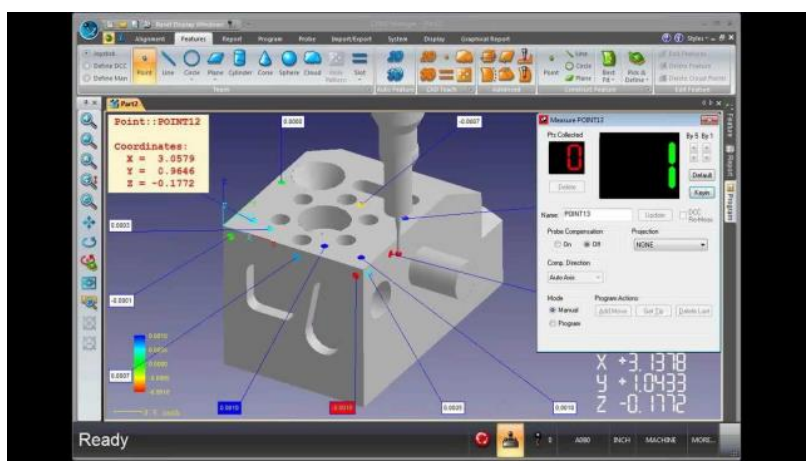

Fig.9. Example of measurement at given points on the $\mathrm{CMM}$ 
The report from the output control showed that all tolerated elevations on the work piece is performed within the required tolerance limits (Fig.10).

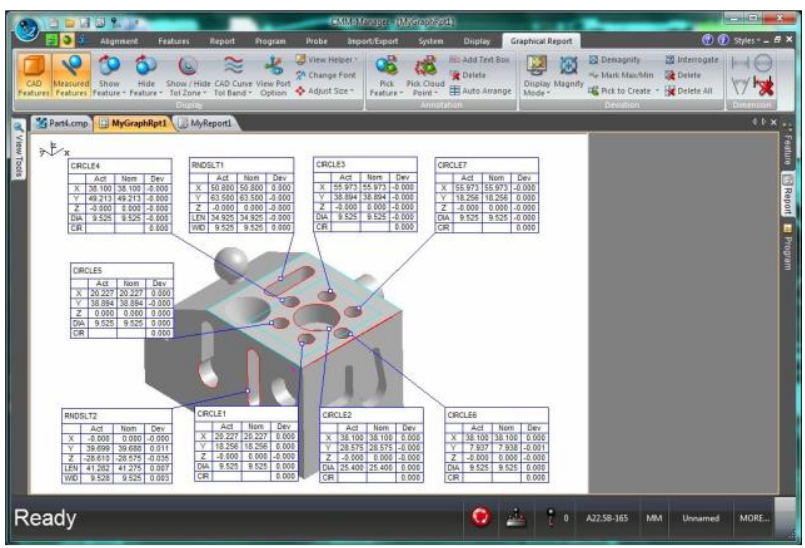

Fig.10. Example of a graphical report on CMM

After completing a test series of one hundred pieces, the autonomous system is put into operation in three shifts all seven days a week (Fig.11). Confirmation of the good choice of components of this flexible cell is the fact that the customer soon ordered four more autonomous systems in the same configuration, also equipped with identical robots to reach the planned production of 375,000 pieces per year.

Measurements performed over the next 6 months yielded the following results:

- the measured average production time is significantly shortened and amounts to 7 minutes, or over 75,000 pieces per year per machine. Saving on production time compared to the previous state of about 13 minutes per piece is $46 \%$;

- reduced number of machines from 10 to 5 . Saving in the color of engaged machines is $50 \%$;

- reduced number of workers needed to service machines from 15 skilled workers to 3 workers which do not require special qualifications. Labor savings are over $80 \%$;

- reduced number of scraps from 3-5\% (of the total number of pieces) to $0 \%$ (measured over a period of 6 months). $100 \%$ savings.

It is also possible to further upgrade the system with $3 \mathrm{D}$ area sensors in order to save the time needed to pack the preparations on special pallets from which the robot takes parts. In that case, the preparations could come with a conveyor belt from a CNC lathe and, instead of on a pallet, be stored in a larger container that is within reach of the robot.

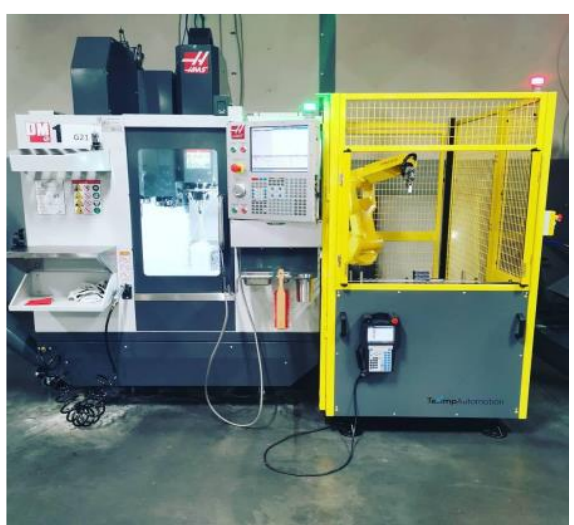

Fig.11. Installed flexible production cell

\section{CONCLUSION}

The complete project is successfully completed with the expected results, which were practically proven. The time of making the work is significantly reduced. The number of engaged machines and people is also significantly smaller. The eventual occurrence of scrap in further exploitation will no longer be measured in percentages, but in units per million pieces (ppm).

From the processed example, it can be concluded that today it is impossible to make production that is sustainable and competitive on the global market without the application of high technology and automation. Connecting different devices into a common network, their mutual communication and autonomy in work is increasingly becoming a necessity.

Increasing the variety of products that market needs impose on manufacturers requires high adaptability of production systems that can be achieved through the introduction of flexible production systems composed of interoperable devices with variable architecture. Control and management of such a complex system requires fast and reliable real-time virtualization of realworld applications as well as real-time feedback from virtual (cyber) real-world models. The boundary line between the actual production system and its cyber-representation is characterized by extremely high permeability of information by merging these two systems into a single system - Cyber-Physical Manufacturing System (CPMS).

It is increasingly certain that the successor to the current CNC machine is the ICNC machine (Intelligent Computer Numerical Control). In the future, we will probably encounter more flexible production cells that are managed by artificial intelligence and that will be able to "learn", and 
human presence will be even less necessary and reduced only to assigning tasks.

Two decades ago, there were less than 700,000 industrial robots worldwide, while today there are over 3 million. In developed countries, there has been a simultaneous increase in production and a decline in employment, and one, though not the only, cause is the development of technologies.

Today, 3D printing is used in the manufacture of cars and airplanes, biotechnology is changing the way we grow crops and produce food and medicine, and the further development of nanotechnology and artificial intelligence will greatly reshape many economic activities, probably faster than we expect.

What is certain is that the current downward trend in the need for unskilled labor whose work can be automated will continue, while the need for professionals who have the skills to develop, launch and maintain such automated systems will grow from year to year.

\section{REFERENCES}

[1] R. Perez, S.C. Gitierez, R. Zotovic, A Study on Robot Arm Machining : Advance and Future Challenges. 29th DAAAM International Symposium on Intelligent Manufacturing and Automation, Vienna, Austria, 2018, pp. 931939.

https://doi.org/10.2507/29th.daaam.proceedi ngs.134

[2] Y. Chen, F. Dong, Robot machining: recent development and future research issues. The International Journal of Advanced Manufacturing Technology, 66, 2013: 14891497.

https://doi.org/10.1007/s00170-012-4433-4

[3] A. Klimchik, A. Ambiehl, S. Garnier, B. Furet, A. Pashkevich, Efficiency evaluation of robots in machining applications using industrial performance measure. Robotics and Computer-Integrated Manufacturing. 48, :2017: 12-29, https://doi.org/10.1016/i.rcim.2016.12.005

[4] L. Cen, S.N. Melkote, Effect of Robot Dynamics on the Machining Forces in Robotic Milling. Procedia Manufacturing, 10, 2017: 486-496. https://doi.org/10.1016/i.promfg.2017.07.034

[5] S. Caro, C. Dumas, S. Garnier, B. Furet, Workpiece placement optimization for machining operations with a KUKA KR270-2 robot. In 2013 IEEE International Conference on Robotics and Automation, May 2013, Karlsruhe, France, pp.2921-2926.

[6] Y. Guo, H. Dong, Y. Ke, Stiffness-oriented posture optimization in robotic machining applications. Robotics and ComputerIntegrated Manufacturing, 35, 2015: 69-76. https://doi.org/10.1016/i.rcim.2015.02.006

[7] A. Pashkevich, A. Klimchik, D. Chablat, Enhanced stiffness modeling of manipulators with passive joints. Mechanism and Machine Theory, 46 (5), 2011: 662-679.

https://doi.org/10.1016/j.mechmachtheory.20 $\underline{10.12 .008}$

[8] M. Tomic, S. Matic-Kekic, L. Savin, E. Desnica, N. Dedovic, M. Simikic, O. Ponjican, A. Asonja, Optimization of the locations of overhaul capacities for agricultural engineering in Serbia by applying integer programming. African Journal of Agricultural Research, 6 (15), 2011: 3346-3354.

[9] C. Dumas, S. Caro, S. Garnier, B. Furet, Joint stiffness identification of six-revolute industrial serial robots. Robotics and Computer-Integrated Manufacturing, 27 (4), 2011: 881-888.

https://doi.org/10.1016/j.rcim.2011.02.003

[10] B. Olofsson, Topics in Machining with Industrial Robot Manipulators and Optimal Motion Control, Department of Automatic Control. Lund University, 2015.

[11] I. Tyapin, G. Hovland, P. Kosonen, T. Linna, Identification of a static tool force model for robotic face milling. In 2014 IEEE/ASME 10th International Conference on Mechatronic and Embedded Systems and Applications (MESA), IEEE, 10-12 September, 2014 Senigallia, Italy, pp.1-6.

https://doi.org/10.1109/MESA.2014.6935591

[12] C. Lehmann, M. Halbauer, D. Euhus, Overbeck, D. Milling with industrial robots: Strategies to reduce and compensate process force induced accuracy influences. In Proceedings of 2012 IEEE 17th International Conference on Emerging Technologies \& Factory Automation (ETFA 2012), IEEE, 17-21 September 2012, Krakow, Poland, pp.1-4. https://doi.org/10.1109/ETFA.2012.6489741

[13] J.W. Jeon, Y.Y. Ha, A generalized approach for the acceleration and deceleration of industrial robots and CNC machine tools. IEEE Transactions on Industrial Electronics, Vol.47 No.1, February 2000, pp.133-139. https://doi.org/10.1109/41.824135 
[14] K. Wu, J. Brueninghaus, B. Johnen, B. Kuhlenkoetter, Applicability of stereo high speed camera systems for robot dynamics analysis. 2015 International Conference on Control, Automation and Robotics, 20-22 May, 2015, Singapore, Singapore, 44-48. https://doi.org/10.1109/ICCAR.2015.7165999

[15] E.O. Ezugwu, W.F. Sales, J. Landre, Machining Dynamics in Turning Processes. SpringerVerlag, London, 2009, pp. 151-166. https://doi.org/10.1007/978-1-84628-368-0

[16] W.S. Owen, E.A. Croft, B. Benhabib, Real-time trajectory resolution for a two-manipulator machining system. J. Robot. Syst., 22, 2006: 51-63. https://doi.org/10.1002/ROB.V22:S1

[17] L. Zhang, J. Deng, S. Chan, A next generation machining system based on NC feature unit and real-time tool path generation, Int. J. Adv. Manuf. Technol., 16, 2000: 889-901. https://doi.org/10.1007/s001700070007

[18] J. Wan, H. Cai, K. Zhou, Industrie 4.0: enabling technologies. In Intelligent Computing and Internet of Things (2015 ICIT), IEEE, 17-18 January 2015, Harbin, China, pp.135-140.

[19] W. Luo, Germany industrial 4.0 strategic enlightenment to China's industrial transformation, Fiber Reinforced Plastics/Composites, 2014. pp.125-128. (in Chinese).
[20] J. Hovey, Robotic Automation of a CNC Machine, Honors Undergraduate Theses. UCF, USA, 2019.

https://stars.library.ucf.edu/honorstheses/662

[21] M Minhat, X.W. Xu, Characteristics and Technologies of Advanced CNC Systems. Encyclopedia of Information Science and Technology. 2009: 519-527.

https://doi.org/10.4018/978-1-60566-0264.ch085

[22] G.M. Martinov, A.B. Ljubimov, A.S. Grigoriev, L.I. Martinova, Multifunction Numerical Control Solution for Hybrid Mechanic and Laser Machine Tool. Procedia CIRP, 1, 2012: 260-264.

https://doi.org/10.1016/j.procir.2012.04.047

[23] S.N. Grigoriev, G.M. Martinov, Decentralized CNC Automation System for Large Machine Tools. The International Conference on Competitive Manufacturing (COMA '13), Stellenbosch, South Africa, 2013, pp. 295-300.

[24] M. Xiong-bo, H. Zhen-yu, W. Yong-zhang, F. Hong-ya, Development of a PC-based Open Architecture Software-CNC System. Chinese Journal of Aeronautics, 20 (3), 2007: 272-281. https://doi.org/10.1016/S1000$\underline{9361(07) 60044-2}$ 